|| Print ISSN: 2589-7837 || Online ISSN: 2581-3935 ||

International Journal of Medical Science and Diagnosis Research (IJMSDR)

Available Online at www.ijmsdr.com

NLM (National Library of Medicine ID: 101738824)

Review Article

Volume 5, Issue 6; June:2021; Page No. 30-42

\title{
ROLE OF PHYSIOTHERAPY IN PREVENTION OF COMPLICATIONS AFTER PARAPLEGIA AND QUADRIPLEGIA
}

Kundu ZS ${ }^{1}$, * Vandana $^{2}$, Verma Vishal ${ }^{3}$

1 MBBS, MS, DNB, MNAMS, Ph.D., Director and Senior Orthopaedic Surgeon of Positron Multispecialty Hospital, Rohtak, Haryana, India

2 BPT, Final year student of Department of Physiotherapy, Guru Nanak Dev University, Amritsar, Punjab, India

${ }^{3}$ MBBS, MS., Consultant Orthopaedic Surgeon of Positron Multispecialty Hospital, Rohtak, Haryana, India

Conflicts of Interest: Nil

Corresponding author: Vandana

DOI: https://doi.org/10.32553/ijmsdr.v5i6.810

\section{Abstract:}

${ }^{1}$ Spinal cord injury is the most frequent and well- defined clinical condition that enterprise functional, physical and psychological impacts. Therefore, SCI patients experience serious medical complications that can profoundly influence patient's identity. ${ }^{2}$ The goal of rehabilitation and other treatment interventions for SCI patients is to enhance ADL activities, decrease morbidity, mortality rate and also help in achieving a fullfilling and active life after SCI. Acute medical complications after SCI is very common but chronic medical complications cause serious negative impact on SCI patients by disturbing their functional and independent life. Therefore, earlier diagnosis and proper treatment interventions play a vital role in limiting these medical complications and achieving independent and quality of life after SCI. in this paper, we review data about common medical complications and preventions in patients of SCI, including cardiovascular impairment, motor and sensory impairment, bladder and bowel dysfunction, osteoporosis and bone metabolism dysfunction, pressure sores, pain syndrome, DVT and pulmonary embolism, infections ( septicemia, pneumonia etc.), psychological and sexual dysfunctions. The purpose of this review is to provide an overview of risk factors, signs, symptoms, prevention and treatment approaches for secondary long-term complications in patients with SCI.

Keywords: spinal cord injury, chronic complications, Management of complications, physical therapy, paraplegia and quadriplegia.

\section{Introduction:}

${ }^{3}$ The most apparent outcome of spinal cord injury (SCI) is paralysis. Paralysis of the muscles below the level of the injury can lead to limited and altered mobility, have to rely on others to complete everyday tasks that were previously done by the patient independently. In addition to the musculoskeletal system, SCI also has extensive effects for many body functions including cardiopulmonary, gastrointestinal, genitourinary and urinary incontinence functions. It also has Psychological distress and change in body images and sexual function.
Rehabilitation play a vital role in achieving a fulfilling and active life after SCI. but in addition patients with SCI also require wheelchair for independent transport, assistant for homecare, house modifications for friendly environment employment for financial supports. Hence management of patient with SCI is relatively high cost involving many healthcare professionals like surgeon, vocational and occupational physiotherapist as physiotherapist play a key role in the rehabilitation process. 
This systematic review layout the role of physiotherapy rehabilitation for patients with SCI and the manifest reinforcing the effectiveness of commonly used physiotherapy interventions. It focus on several complications due to spinal cord injury (SCI) including spinal shock, contractures , pressure sores, poor sensory and motor control, osteoporosis etc. complications and rehabilitation phase are discussed here, although physiotherapist play a vital role just after injury and also after discharge from the hospital.

\section{Types of spinal cord injury}

${ }^{4}$ Spinal cord injury is relatively short- prevalence disability affecting predominantly younger males, although older adults are experiencing SCI likely due to falls, and SCI is associated with lengthy and costly care.

${ }^{5}$ Spinal cord injury can be grossly divided in two etiological categories and these are: -

1. Traumatic injuries

2. Non- Traumatic injuries

\section{Traumatic injuries}

Trauma is the most common cause of spinal cord injury especially in young population and injury occur may be due to RSA (Road side

Accidents) or violence or falls or in sports activities.

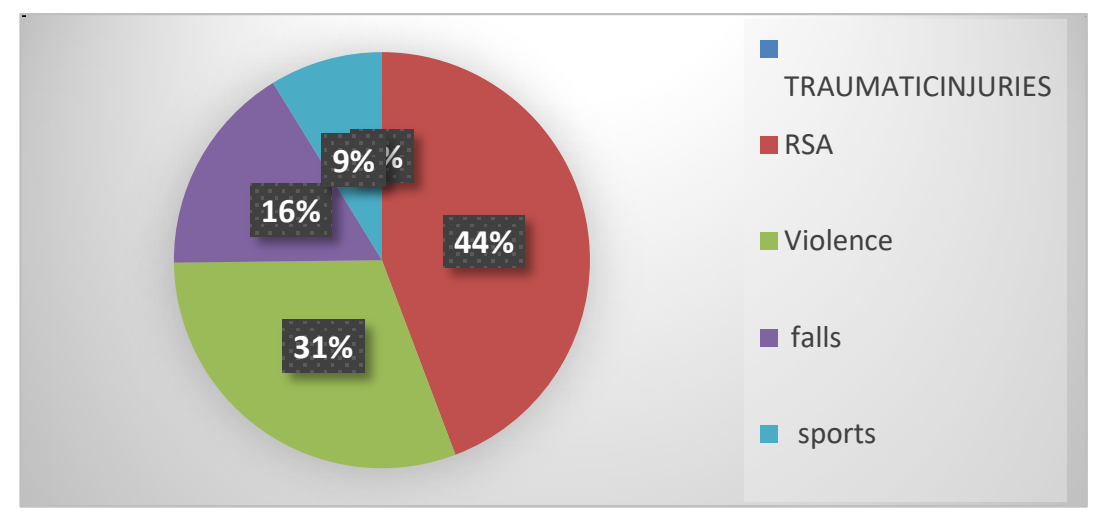

\section{Non-Traumatic Injuries}

\section{Graph 1:}

${ }^{6}$ Non -Traumatic injuries occur in adult population due to pathological or disease which may be as follows: -

- Arteriovenous malformation (AVM)

- Vertebral subluxation

- Spinal neoplasm

- Syringomyelia

- Spinal cord infections.

${ }^{7}$ Non - Traumatic etiologies account for approximately $39 \%$ of all SCIs.

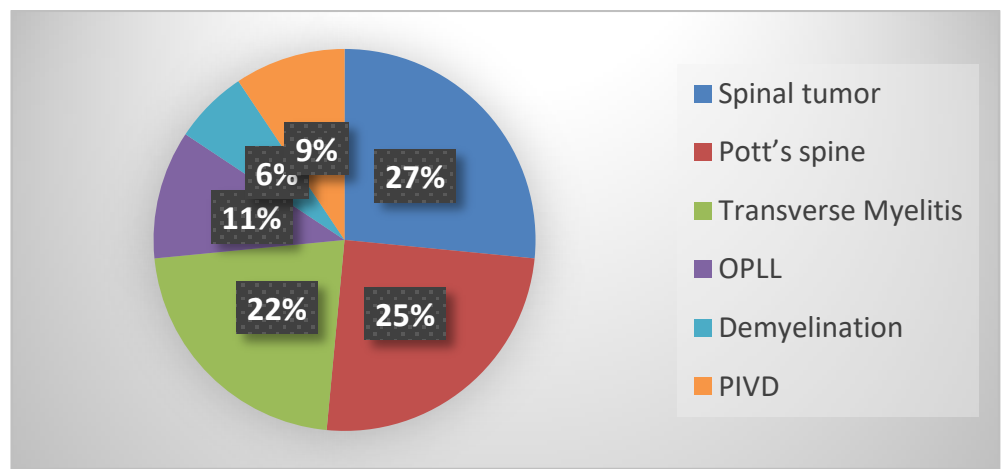

Graph 2: 


\section{Non-Traumatic Injury}

Types of spinal cord injury

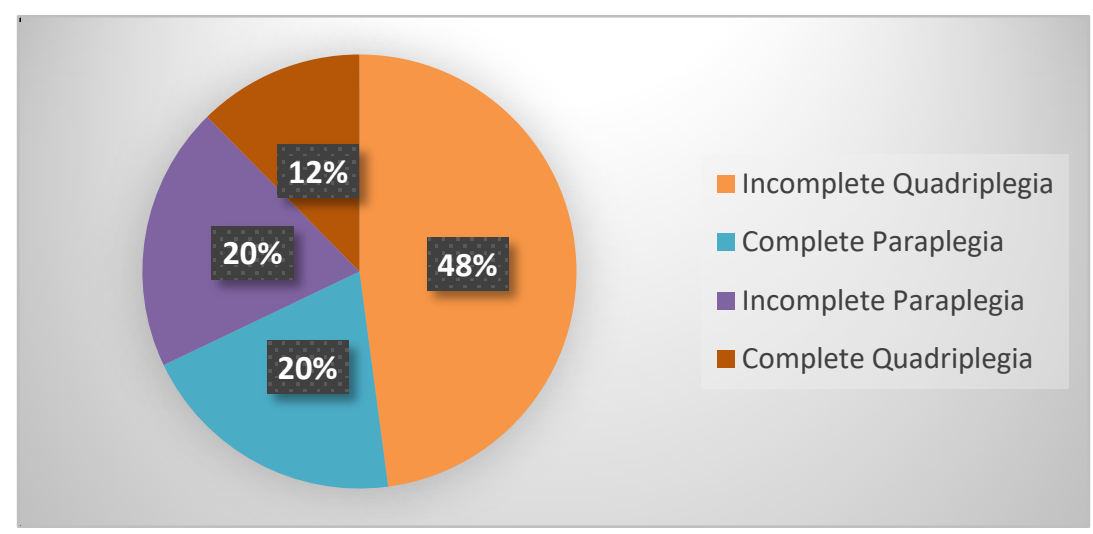

Graph 3:

Spinal cord injury typically divided into two broad categories and these are as follows:

${ }^{8}$ Paraplegia refers to complete paralysis of all or part of the trunk and lower extremities. This condition is typically caused from lesions of the thoracic or lumbar spinal cord or cauda equina.

${ }^{9}$ Quadriplegia refers to paralysis from the neck down, including the trunk, legs and arms. This condition is typically caused by an injury to the spinal cord that contain the nerves that transmit messages of movement and sensation from the brain to parts of the body.

\section{Complications and Preventions}

\section{Cardiovascular Impairment}

${ }^{10}$ In healthy individuals with an intact spinal cord, cardiovascular function is regulated by the brainstem and hypothalamus via the sympathetic and parasympathetic nervous systems.

Parasympathetic signals to the heart arise from the vagus nerve, decreasing heart rate and contractility on the other hand Sympathetic input increases heart rate and contractility and peripheral vasoconstriction.

Following SCI will result in a loss of sympathetic communication between the brainstem and the heart, while parasympathetic input remains intact which will causes bradycardia and dilation of the peripheral vasculature below the level of the lesion.
Due to disrupted balance between sympathetic and parasympathetic input, as well as a lack of or decrease in active muscle contraction and prolonged time in bed, orthostatic hypotension is often experienced during early transitions to a more upright posture.

\section{Recommendations}

- ${ }^{11}$ Initially begins with elevation of the head of the bed and progresses to a reclining wheelchair with elevating leg rests and use of a tilt table that is slow progression from supine to standing is allowed to avoid side effects in early after SCI.

- Compressive stockings and an abdominal binder are also advised to the patient to minimize side effects.

- A regular cardiovascular fitness exercise program is an important component of rehabilitation.

- Endurance training in quadriplegics and paraplegics can elicit improvements in exercise performance similar to those observed in ablebodied individuals.

\section{Bladder and Bowel Dysfunction}

\section{Bladder Dysfunction}

12 Bladder dysfunction is a significant complication in patients with SCI which not only effect the patients physically but also effect psychologically as it increase urinary system disturbance in the SCI patients. 
There are three areas of the central nervous system include cerebral cortex, pontine micturition center and sacral micturition center who control the bladder functions. ${ }^{13}$ Pontine and sacral micturition center can be intersperse by central lesion. Peripheral lesion mainly effect muscles of bladder include detrusor muscle and external urethral sphincter could cause urinary system disturbance.

There are various clinical conditions occur in neurogenic bladder after SCI patients in terms of detrusor muscle and external urethral sphincter activity. These conditions includes 1). Hyperreflexic detrusor muscle with involuntary condition of sphincter muscle.2). Hyperreflexic detrusor muscle with sphincter areflexic with reflex incontinence.3).areflexic detrusor muscle with sphincter hyperreflexic with overflow incontinence and urinary retention.4). Areflexic condition of both detrusor and sphincter muscle.

${ }^{14}$ The effects of bladder dysfunction following SCI cause Urinary tract infections (UTIs) which is a major cause of mortality and morbidity in people with SCI. Spinal cord injury alters the complex reflexive and voluntary control of micturition. As a result, people with SCI often require a catheter to drain the bladder. Spinal control for micturition originates from the sacral segments of S2, S3, and S4.5 he level of the SCI dictates the type of bladder dysfunction.

${ }^{15}$ The primary goal of bladder management is to make the patient catheter free, have low post void residual volume of urine in the bladder, and be without high bladder pressure during voiding.

The exact method or combination of methods used for bladder management will depend on a variety factors: type of bladder dysfunction, level of injury, functional ability, and personal preference.

- Intermittent catherization is the most common method of bladder management after discharge from the rehabilitation hospital.

- Bladder training to help the bladder return to normal function.
- Strengthening exercises for the pelvic floor muscles.

- Strengthening exercises for the abdominal muscles.

- Biofeedback training to show you how well you are using your pelvic floor muscles.

Systematic inspection and proper management protocol for bladder dysfunction are crucial to avoid further long term complications like infections, vesicouretheral reflux, renal failure, renal calculi, and bladder cancer and provide a quality full life to the SCI patients.

\section{Bowel Dysfunction}

${ }^{16}$ Neurogenic bowel is a significant complication in patients with SCI which not only effect the patients physically but also effect psychologically. ${ }^{17}$ It is the commonest complication effecting about half of the patients with SCI. ${ }^{18}$ There are several factors include high level of cord lesion, prolonged duration of injury and completeness of cord injury which can enhance severity of neurogenic bowel in patients with SCI.

${ }^{19}$ Due to lack of nervous control colon dysfunction may occur which leads to occurrence of neurogenic bowel. There are two types of neurogenic bowel include upper motor neuron bowel syndrome and lower motor bowel syndrome.

${ }^{20}$ Upper motor neuron bowel syndrome results spinal cord lesion above conus medullaris on the other hand lower motor neuron bowel syndrome results from a lesion effecting conus medullaris, cauda equina or the pelvic nerve. In upper motor neuron bowel syndrome there is voluntary control of external anal sphincter is interrupted but the sphincter remain tight which leads to constipation and fecal retention and on the other hand LMN bowel syndrome or areflexic bowel there is involuntary control of external anal sphincter and the levator ani muscle leads to lack of spinal cord mediated reflex peristalsis and slow stool propulsion. 
${ }^{17}$ About $39 \%$ of SCI patients suffering from bowel dysfunction severely affect their social activities and also their quality of life. Bowel dysfunction management is more important because it could cause more complications than both bladder and sexual dysfunction.

There are several physiotherapy interventions for management of bowel dysfunction in SCI patients include ${ }^{21}$ abdominal massage, ${ }^{22}$ rectal electric stimulation, ${ }^{23}$ high dietary fibres intake, colonic electric stimulation and functional electric and magnetic stimulation of skeletal muscles.

${ }^{24}$ These conservative or pharmacological treatment protocol play a significant role in bowel dysfunction management for about $67 \%$ SCI patients and in remaining cases surgery intervention include colostomy, sacral nerve stimulation with implantation of electrical stimulation systems and Malone antegrade continence enema play significant role in bowel dysfunction management.

\section{Motor and Sensory Impairments}

Subsequently SCI there will be either complete (paralysis) or partial (paresis) loss of muscle function below the level of the lesion and impaired or absent sensation below the level of the lesion due to disruption of the ascending sensory fibres.

\section{Recommendations}

- ${ }^{24,25}$ Motor and sensory function should be assessed using the ISNCSCI to determine the level of neurological injury.

- Care should be taken when performing manual muscle testing particularly in case of unstabilized spine and Forceful contraction of muscles should be avoided which may cause instability at the fracture site.

- Discretion should be used in applying resistance around the shoulders in tetraplegia and around the lower trunk and hips in paraplegia.

- Gait training play a vital role in motor learning after spinal cord injury in people with the potential to walk. Again, repetitive practice is a key component.
- The patient needs to practice walking with orthoses and walking aids if the patient has extensive paralysis.

- In contrast, Treadmills and robotic devices can be used for neurological recovery and to make gait training easier and to provide an opportunity for intensive repetitive practice using a gait strategy that mimics that of an able-bodied person.

- Cyclic walking promotes neural plasticity within the spinal cord and the 'training' of central pattern generators; a complex reflex of the spinal cord.

\section{Sexual Dysfunction}

Spinal cord injury not only affects the physiological ability to have intercourse but also effect the psychosocial aspect of sexuality.

\section{Female Response}

- ${ }^{26,27}$ Patients with UMN lesions, the reflex arc remains intact therefore reflexogenic stimulation will occur, but psychogenic response will be lost. On the other hand with LMN lesions, psychogenic responses will remain intact and reflex responses lost.

- Fertility is not affected as severely in women as men with SCI.

- The menstrual cycle typically is interrupted for a period of 4 to 5 months following injury.

- Women with SCI who want to bear children should be closely supervised during pregnancy.

- They are more likely to encounter complications during pregnancy and childbirth than woman without SCI.

\section{Male Response}

- ${ }^{26,27}$ Sexual capabilities are broadly divided between UMN (damage to the cord above S2-S4) and LMN lesions.

- Erectile capacity is greater in UMN lesions than in LMN lesions and greater in incomplete lesions than in complete lesions. There are two types of erections: reflexogenic and psychogenic.

- The low level of fertility was associated with impaired spermatogenesis and an inability to ejaculate. 


\section{Recommendations}

Treatment of sexual dysfunction is categorized into three interventions which should be fulfilled by the therapist to bring out all the essential information from the patient which is mandatory for sexual rehabilitation purpose and these are as follows: -

1. Permission is the first level of intervention in which the therapist verbally seek for patient's permission to ask about sexual issues and legitimizes their concerns. Normalization is a key component to the success of this intervention.

2. The second level of intervention is limited information, in this the therapist gather only factual information that is directly relevant to their particular sexual issue: awareness of the most commonly experienced sexual dysfunctions, or knowledge of available sexual health services in the local community.

3. To provide the third level of intervention, specific suggestions, the clinician must have training in sexual health such that they can offer appropriate therapies or recommendations for a client's specific concerns. This could include offering a man with a spinal cord injury a trial of a PDE-5 inhibitor for erectile dysfunction.

Finally, intensive therapy involves highly specialized assessment and treatment, which is typically limited to dedicated sexual health clinicians or other specialists with specific training and experience.

\section{Infections: Septicemia and Pneumonia}

\section{Septicemia}

${ }^{28,29}$ One of the most frequent and life-threatening complications after SCI is sepsis especially in ICU patients who need mechanical ventilation support very badly and along with this pulmonary and infectious complications are also reported.

${ }^{30,31}$ Septicemia was caused by staphylococcus aureus and about $30 \%$ of SCI patients are suffering from this life threatening complication. $^{32,33}$ If not treated on time it may lead to respiratory complications, organ failure and even death. ${ }^{33,35}$ Sepsis can be caused from any type of infection and also vary between different population as 12.1 to 57.8 per million people with traumatic type of spinal cord injury are suffering from sepsis and about 6.0 to 8.6 per million people with non- traumatic type of spinal cord injury are suffering from sepsis.

Sepsis is a serious medical condition which should be treated as earlier as possible by doing proper diagnosis includes blood and urine test, CT scan. There is no standard physiotherapy treatment but can be treated by using vasopressor medications to reach an adequate blood pressure, IV fluids to avoid drooping of blood pressure, mechanical ventilation to prevent from further respiratory complications and appropriate supportive care .

\section{Pneumonia}

${ }^{36}$ There are various most important and frequent forms of pulmonary complications after spinal cord injury include Pneumonia, thromboembolism, pulmonary infarction, chest injury and atelectasis. Out of these pneumonia is one of the most vital pulmonary complication in pulmonary dysfunction. Pneumonia develop in very short period of time may be during hospitalization or in rehabilitation period. Pneumonia is very risky in post - injury period when it is asymptomatic.

Ventilator associated pneumonia is chronic nosocomial infection develop after intubation and mechanical ventilation result in prolonged intense care unit with mechanical ventilation stay and lead to high risk of morbidity and mortality.

The primary goal of physiotherapy intervention is to increase ventilatory technique and proper secretion clearance. There is a standard physiotherapy protocol for management for pneumonia includes some massage techniques (percussions, vibrations and shaking), deep breathing exercises (spirometry and inspiratory muscle training). To improve proper ventilation continuous positive airway pressure (CPAP) and bi-level positive airway pressure (BiPAP) are used. 


\section{Pressure ulcers}

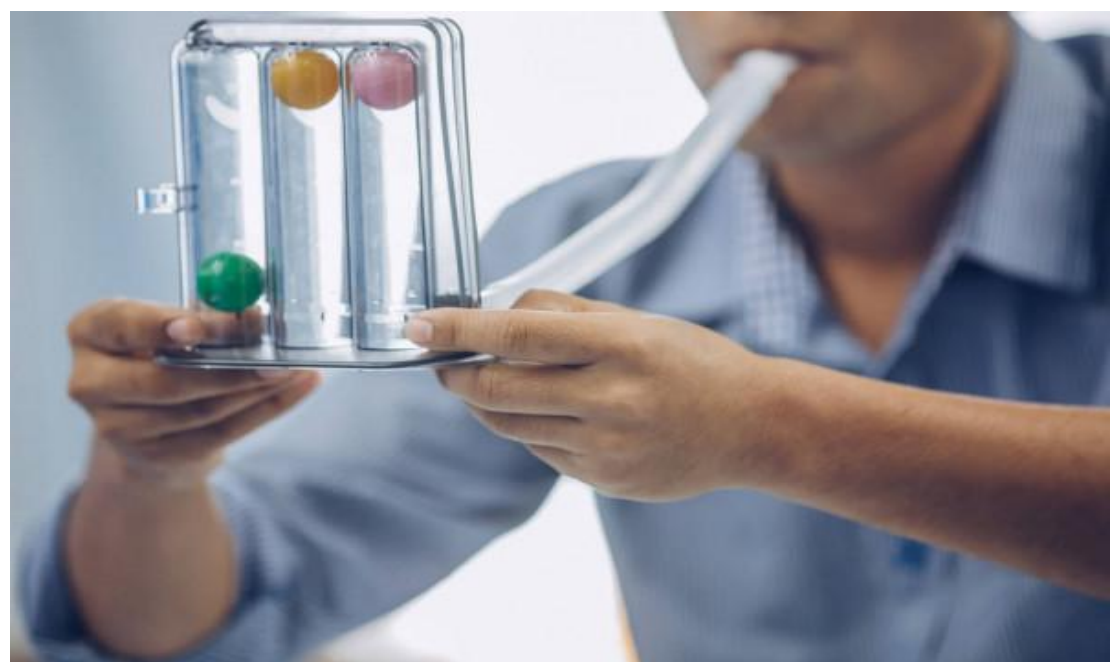

Figure 1: Spirometry (Deep Breathing Exercise)

${ }^{37}$ Pressure sores are the commonest secondary medical complication post spinal cord injury. Patients with pressures sores exhibited significantly diminished physical and social function, self-care and mobility. Mortality is associated with pressure sores but it do not cause death; rather the pressure sore is associated with a sequential decline in health status which is then associated with mortality. The most common sites of pressure ulcers is pelvic region i.e. affecting the sacrum, coccyx, ischial tuberosities and trochanters.

\section{Recommendation}

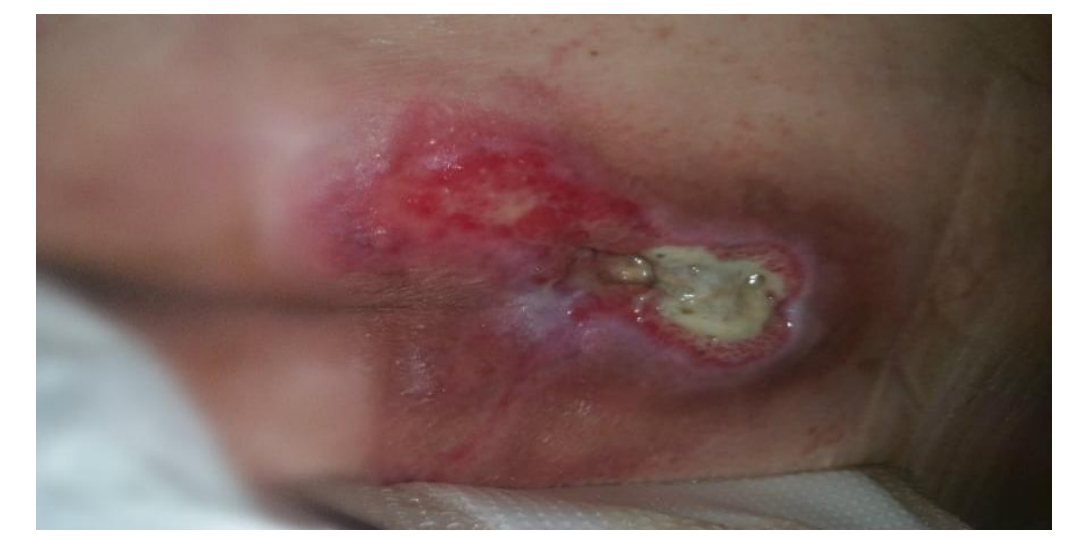

Figure 2:

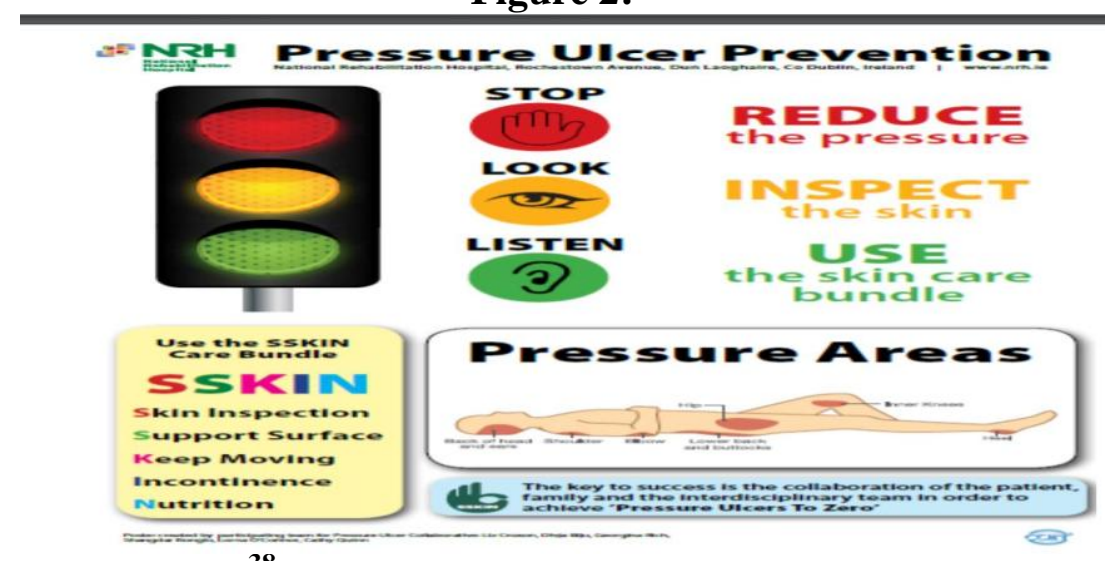

38 Figure 3: prevention of bed sore 
- Transfers and gait re-education.

- Changing position of the patient every two hour.

- Passive movement and stretching in bed.

- Use of anti -fungal powders.

- Positioning into prone.

- Sitting for specific period.

- Ultrasound and laser were the commonest (54\%) modalities used by physiotherapists to strengthen and for functional training like bed mobility etc.

\section{Contractures}

${ }^{39}$ Contractures resulting in limitation in motion due to prolonged shortening of structures across and around a joint. There are some associated factors which are responsible for increasing risk of contractures after SCI and these are spasticity, positioning in wheelchair or bed for prolonged periods of time, and abnormal muscle tone. The most common site of contractures are of the ankle, knee, hip, elbow, and shoulder joints.

\section{Recommendations}

- Range of motion (ROM) exercises

- Positioning

- splinting

Therefore, it is important to maintain joint motion and prevent contracture.

\section{Pain}

${ }^{40,41}$ Pain is a commonest complication following SCI both in the acute and chronic stages of recovery which can limit the performance of activities of daily living (ADL), affect sleep, and contribute to a lower quality of life. ${ }^{42}$ Pain can be grossly divided into two broad categories: nociceptive pain and neuropathic pain. Nociceptive pain can be musculoskeletal or visceral in origin. ${ }^{43,44}$ Neuropathic pain can be below, at, or above the level of injury.

\section{Recommendations}

- Transcutaneous electrical nerve stimulation (TENS),

- Massage

- Acupuncture and mental imagery.

- Walking aids

- NSAIDS

\section{Bone metabolism dysfunction \\ - Osteoporosis and Bone fractures}

${ }^{45}$ Osteoporosis or silent thief disease is a metabolic bone disease characterized by reduced bone mass is a most notable complication of SCI. ${ }^{46}$ Rate of osteoporosis is very fast in initial 12-18 months and then remain constant for several years. ${ }^{47,48,49}$ It is characterised by decrease bone density due to decrease bone mass as rate of bone absorption is more than bone formation has been described in chronic SCI patients.

There are several complex and multifactorial etiologies which are involved in development of SCI induced osteoporosis. Senility and menopause are the most common factors in males and female respectively in developing SCI induced pathogenesis. ${ }^{45}$ There are some other important factors include post immobilization, malnutrition, protein deficiency, long term steroid therapy and other endocrine disorders.

${ }^{50}$ Loss of bone mass leads to loss of strength thus increase chances of minimal impact fractures. The most frequent site for fracture is dorso- lumbar spine, neck of femur and colle's fracture. Osteoporosis is a multifactorial bone disease include level of lesion, bone muscle loading, extension of injury and ageing have a dominant impact on bone mass in SCI patients. ${ }^{51}$ The degree of loss of bone mass may vary in complete or incomplete types of spinal cord injury. Bone muscle loading play a vital role in maintenance of bone density.

${ }^{52}$ No standard treatment protocol for management of osteoporosis in SCI patients is available but medications and rehabilitation oriented approaches were reported significant role in management of osteoporosis for SCI patients.

${ }^{53}$ Physiotherapy interventions which play important role in management of osteoporosis for SCI patients include gait training with walking aids, weight bearing physical exercises, functional electric stimulation. In early phase of SCI, orthotically walking aids appear to have beneficial effects. 
10. Deep vein thrombosis and Pulmonary Embolism

${ }^{54}$ Deep vein thrombosis and pulmonary embolism are prominent early complications of an acute spinal cord injury.

${ }^{55}$ About $24 \%$ of SCI patients are suffering from deep vein thrombosis. Apart from relapse, late DVT complications are more severe and can cause post thrombotic, spastic paralysis, ulcerations, trophic autonomic dysreflexic and trophic skin changes. Hence DVT is one of the major complication of spinal cord injury.

Deep vein thrombosis is more common in paraplegic patients than quadriplegic patients and the most fascinating thing to note is that all paraplegic patients with DVT also has spastic paralysis.

${ }^{56}$ Pulmonary embolism is certainly life threatening condition and crucial cause for Morbidity and mortality among SCI patients. About $4.5 \%$ of SCI patients are suffering from pulmonary embolism but it is poorly diagnosed in initial months after SCI. High rate of pulmonary embolism is reported in complete spinal cord injury and there is no difference in pulmonary embolism rate in paraplegia and tetraplegia.

Both pharmacological and physiotherapy interventions play a vital role in management of deep vein thrombosis and pulmonary embolism .Physiotherapy intervention includes compression stockings or bandages, intermittent pneumatic compression(IPC) and venous foot pumps play a vital role in improving deep veins blood flow in legs. Pharmacological interventions include heparin both unfractionated and low molecular weight. Mobility is very important in pulmonary embolism recovery. Anticoagulation and thrombolytic therapies along with bed rest play a vital role in pulmonary embolism management

\section{Psychological Dysfunction}

${ }^{57}$ People with SCI, aged between mid-twenties to late forties, are more prone to depression then younger and depression occurred more commonly among women lacking emotional support, whereas a higher prevalence of depression existed among men wanting tangible support.

\section{Recommendations}

- Yoga and medications

- Group therapy sessions

- Proper counselling sessions

- Participation in social activities

- Family and friends support

- Proper sleep

12. Balance and coordination Dysfunction

${ }^{58}$ Due to fracture and dislocation of spine in spinal cord injury, patient lose balance and coordination especially of upper limb muscles, hip and thigh muscle hence unable to do certain activities includes upright sitting on bed, walking, improper gait pattern etc. There are certain exercise and training for the SCI patients which would be helpful in restoring balance and coordination. For strengthening of Upper limb muscles in which chest stretching occur includes certain activities like table tennis, netball and archery helpful. Juvenile throw like game activities help in restoring shoulder girdle muscles. There are certain manual techniques includes PNF, biofeedback, passive exercise and strengthening exercise that are useful in making the patient to sit upright on bed followed by arm outstretched hands to maintain balance and coordination. Some activities like throw ball help in restoring sense of balance. Gait training in parallel bar play a vital role in restoring balance and coordination in walking and also improve gait pattern.

\section{Urinary Tract Infection (UTIs)}

About $80 \%$ SCI patients died due to urinary infection. UTI cause serious infectious complications in bladder and kidney. Hence there are certain objective for management of UTI includes prevent infection from bladder and renal tract, avoid pooling of residual urine back into bladder to prevent from infection, prevent formation of vesicle calculi which would formed due to residual urine and infections, avoid over distension and contraction of bladder which would encourage infections. There are certain pre warning sign of bladder distension includes vague suprapubic discomfort sweating, buttock and 
pennis pain. If patient was trained about these warning sign than patient would do emptying reflex activity immediately by contraction of abdominal muscles, applying stimuli to the skin of groin, lower abdomen and pennis. There are various methods for UTI management includes overflow incontinence with manual compression, indwelling urethral catheter, high cystostomy with tidal drainage, deep breathing streaning of trunk muscles and adaptation of upright posture for reflex emptying.

\section{References}

1. Myers J, Lee M, Kiratli J. Cardiovascular disease in spinal cord injury: an overview of prevalence, risk, evaluation, and management. Am J Phys Med Rehabil 2007;86:142-152. [PubMed] [Google

Scholar]

2. Sezer, N., Akkuş, S., \& Uğurlu, F. G. (2015). Chronic complications of spinal cord injury. World journal of orthopedics 6(1),24-33.

https://doi.org/10.5312/wjo.v6.i1.24.

3. Lisa A Harvey, Physiotherapy rehabilitation for people with spinal cord injuries, Journal of Physiotherapy, Volume 62, Issue 1, 2016, Pages 4-11, ISSN 1836-9553, https://doi.org/10.1016/j.jphys.2015.11.004.

4. O'Sullivan, Susan B.; Schmitz, Thomas J.; and Fulk, George D., "Physical Rehabilitation, 6th edition" (2014). Faculty Bookshelf.85.

https://hsrc.himmelfarb.gwu.edu/books/85.

5. DeVivo, MJ, and Chen, Y: Trends in new injuries, prevalent cases, and aging with spinal cord injury. Arch Phys Med Rehabil 92(3):332, 2011.

6. National Spinal Cord Injury Statistical Center: Spinal Cord Injury: Facts and Figures at a Glance. Retrieved July 22, 2011, from www.nscisc.uab.edu

7. Lundy-Ekman, L: Neuroscience: Fundamentals for Rehabilitation, ed 3. Saunders, Philadelphia, 2007.

8. Eckert MJ, Martin MJ. Trauma: Spinal Cord Injury. Surg Clin North Am. 2017 Oct; 97(5):1031-1045.
9. Harvey L. A. (2016). Physiotherapy rehabilitation for people with spinal cord injuries. Journal of physiotherapy,62(1),411.

https://doi.org/10.1016/j.jphys.2015.11.004.

10. Martin, JH: Neuroanatomy Text and Atlas, ed 2. Appleton \& Lange, Stamford, CT, 1996. 39.

11. Hoffman, M.D. Cardiorespiratory Fitness and Training in Quadriplegics and Paraplegics. Sports Medicine 3, 312-330 (1986). https://doi.org/10.2165/00007256198603050-00002

12. Hagen EM, Faerestrand S, Hoff JM, Rekand T, Gronning M. Cardiovascular and urological dysfunction in spinal cord injury. Acta Neurol Scand Suppl. 2011;(191):71-

78. [PubMed] [Google Scholar].

13. Benevento BT, Sipski ML. Neurogenic bladder, neurogenic bowel, and sexual dysfunction in people with spinal cord injury. Phys Ther. 2002;82:601612. [PubMed] [Google Scholar]

14. Benevento, BT, and Sipski, ML: Neurogenic bladder, neurogenic bowel, and sexual dysfunction in people with spinal cord injury. Phys her 82(6):601, 2002.

15. Taweel, W. A., \& Seyam, R. (2015). Neurogenic bladder in spinal cord injury patients. Research and reports in urology, 7,85-99. https://doi.org/10.2147/RRU.S29644.

16. Krassioukov A, Eng JJ, Claxton G, Sakakibara BM, Shum S. Neurogenic bowel management after spinal cord injury: a systematic review of the evidence. Spinal Cord. 2010;48:718-733. [PMC free article] [PubMed] [Google Scholar]

17. 45. Liu CW, Huang CC, Yang YH, Chen SC, Weng MC, Huang MH. Relationship between neurogenic bowel dysfunction and health-related quality of life in persons with spinal cord injury. J Rehabil Med. 2009; 41:35-40. [PubMed] [Google Scholar]

18. 46. Liu CW, Huang $\mathrm{CC}$, Chen $\mathrm{CH}$, Yang YH, Chen TW, Huang MH. Prediction of severe neurogenic bowel dysfunction in 
persons with spinal cord injury. Spinal Cord. 2010;48:554-559. [PubMed] [Google Scholar]

19. 47. Stiens SA, Bergman SB, Goetz LL. Neurogenic bowel dysfunction after spinal cord injury: clinical evaluation and rehabilitative management. Arch Phys Med Rehabil. 1997;78:S86-

102. [PubMed] [Google Scholar]

20. 48. Ebert E. Gastrointestinal involvement in spinal cord injury: a clinical perspective. $\mathbf{J}$ Gastrointestin Liver Dis. 2012;21:7582. [PubMed] [Google Scholar]

21. Cameron KJ, Nyulasi IB, Collier GR, Brown DJ. Assessment of the effect of increased dietary fibre intake on bowel function in patients with spinal cord injury. Spinal Cord. 1996;34:277-283. [PubMed] [Google Scholar]

22. Ayaş S, Leblebici B, Sözay S, Bayramoğlu $M$, Niron EA. The effect of abdominal massage on bowel function in patients with spinal cord injury. Am J Phys Med Rehabil. 2006;85:951-

955. [PubMed] [Google Scholar]

23. Korsten MA, Singal AK, Monga A, Chaparala G, Khan AM, Palmon R, Mendoza JR, Lirio JP, Rosman AS, Spungen A, et al. Anorectal stimulation causes increased colonic motor activity in subjects with spinal cord injury. J Spinal Cord Med. 2007;30:31-35. [PMC free article] [PubMed] [Google Scholar]

24. Harvey L. A. (2016). Physiotherapy rehabilitation for people with spinal cord injuries. Journal of physiotherapy, 62(1), 411. https://doi.org/10.1016/j.jphys.2015.11. 004

25. O'Sullivan, Susan B.; Schmitz, Thomas J.; and Fulk, George D., "Physical Rehabilitation, 6th edition" (2014). Faculty Bookshelf.85.

https://hsrc.himmelfarb.gwu.edu/books/85.

26. Watanabe, $\mathrm{T}$, et al: Epidemiology of current treatment for sexual dysfunction in spinal cord injured men in the USA model spinal cord injury centers. J Spinal Cord Med 19(3):186, 1996.
27. Elliott, S: Sexuality after spinal cord injury. In Field-Fote, EC (Ed): Spinal Cord Injury Rehabilitation. FA Davis, Philadelphia, 2009.

28. Vincent JL, Sakr Y, Sprung CL, Ranieri VM, Reinhart K, Gerlach H, et al. Sepsis in European intensive care units: results of the SOAP study. Crit Care Med. 2006; 34:34453.

29. Otto GP, Sossdorf M, Claus RA, Rodel J, Menge K, Reinhart K, et al. The late phase of sepsis is characterized by an increased microbiological burden and death rate. Crit Care. 2011;15:R183.

30. Hotchkiss RS, Monneret G, Payen D. Immunosuppression in sepsis: a novel understanding of the disorder and a new therapeutic approach. Lancet Infect Dis. 2013;13:260-8.

31. Singer M, Deutschman CS, Seymour CW, Shankar-Hari M, Annane D, Bauer M, et al. The Third International Consensus Definitions for Sepsis and Septic Shock (Sepsis-3). JAMA. 2016;315:801-10.

32. Cecconi M, Evans L, Levy M, Rhodes A. Sepsis and septic shock. Lancet (Lond, Engl). 2018;392:75-87.

33. Kriz J, Kulakovska M, Davidova H, Silova M, Kobesova A. Incidence of acute spinal cord injury in the Czech Republic: a prospective epidemiological study 20062015. Spinal Cord. 2017;55:870-4.

34. New PW, Sundararajan V. Incidence of non-traumatic spinal cord injury in Victoria, Australia: a population-based study and literature review. Spinal Cord. 2008;46: 406-11.

35. van den Berg ME, Castellote JM, MahilloFernandez I, de Pedro-Cuesta J. Incidence of spinal cord injury worldwide: a systematic review. Neuroepidemiology. 2010; 34:184-92. discussion 92

36. Farhad Abbasi and Soolmaz Korooni (December 20th 2017). Infectious Complications after Spinal Cord Injury, Essentials of Spinal Cord Injury Medicine, Yannis Dionyssiotis, IntechOpen, DOI:10.5772/intechopen.72783. 
37. D, Pather \& Mudzi, Witness. (2013). An audit of the Physiotherapy management of paraplegic patients with sacral pressure sores. South African Journal of Physiotherapy. Special Edition. 55 - 61. 10.4102/sajp.v69i4.380.

38. Guihan, M., Hastings, J., \& Garber, S. L. (2009). Therapists' roles in pressure ulcer management in persons with spinal cord injury. The journal of spinal cord medicine, 32(5), 560-567. https://doi.org/10.1080/10790268.2009.117 54561.

39. Katalinic, OM, Harvey, LA, and Herbert, RD: Effectiveness of stretch for the treatment and prevention of contractures in people with neurological conditions: A systematic review. Phys her 91(1):11, 2011.

40. Widerstrom-Noga, EG, et al: Perceived difficulty in dealing with consequences of spinal cord injury. Arch Phys Med Rehabil 80(5):580, 1999.

41. Dijkers, M, Bryce, $\mathrm{T}$, and Zanca, J: Prevalence of chronic pain after traumatic spinal cord injury: A systematic review. J Rehabil Res Dev 46(1):13, 2009.

42. Widerstrom-Noga, EG, Felipe-Cuervo, E, and Yezierski, RP: Chronic pain after spinal injury: Interference with sleep and daily activities. Arch Phys Med Rehabil 82(11):1571, 2001.

43. Westgren, N, and Levi, R: Quality of life and traumatic spinal cord injury. Arch Phys Med Rehabil 79(11):1433, 1998.

44. Widerstrom-Noga, EG: Pain after spinal cord injury: Etiology and management. In Field-Fote, EC (Ed): Spinal Cord Injury Rehabilitation. FA Davis, Philadelphia, 2009.

45. Jiang SD, Dai LY, Jiang LS. Osteoporosis after spinal cord injury. Osteoporos Int. 2006;17:180-192. [PubMed] [Google Scholar]

46. Middleton JW, Leong G, Mann L. Management of spinal cord injury in general practice - part 2. Aust Fam Physician. 2008;37:331-32, 335-338. [PubMed] [Google Scholar]
47. Lazo MG, Shirazi P, Sam M, GiobbieHurder A, Blacconiere MJ, Muppidi M. Osteoporosis and risk of fracture in men with spinal cord injury. Spinal Cord. 2001;39:208-214. [PubMed] [Google Scholar]

48. 81. Vlychou M, Papadaki PJ, Zavras GM, Vasiou K, Kelekis N, Malizos KN, Fezoulidis IB. Paraplegia-related alterations of bone density in forearm and hip in Greek patients after spinal cord injury. Disabil Rehabil. 2003;25:324330. [PubMed] [Goog le Scholar]

49. 82. Zehnder Y, Lüthi M, Michel D, Knecht H, Perrelet R, Neto I, Kraenzlin M, Zäch G, Lippuner K. Long-term changes in bone metabolism, bone mineral density, quantitative ultrasound parameters, and fracture incidence after spinal cord injury: a cross-sectional observational study in 100 paraplegic men. Osteoporos Int. 2004;15:180-189. [PubMed] [Google Scholar]

50. Morse LR, Giangregorio L, Battaglino RA, Holland R, Craven BC, Stolzmann KL, Lazzari AA, Sabharwal S, Garshick E. VAbased survey of osteoporosis management in spinal cord injury. PM R. 2009;1:240244. [PMC free article] [PubMed] [Google Scholar]

51. 84. Giangregorio L, McCartney N. Bone loss and muscle atrophy in spinal cord injury: epidemiology, fracture prediction, and rehabilitation strategies. J Spinal Cord Med. 2006;29:489-500. [PMC free article] [PubMed] [Google Scholar]

52. Biering-Sørensen F, Hansen B, Lee BS. Non-pharmacological treatment and prevention of bone loss after spinal cord injury: a systematic review. Spinal Cord. 2009;47:508-518. [PubMed] [Google Scholar]

53. Charmetant C, Phaner V, Condemine A, Calmels P. Diagnosis and treatment of osteoporosis in spinal cord injury patients: A literature review. Ann Phys Rehabil Med. 2010;53:655-668. [PubMed] [Google Scholar] 
54. Aito S, Pieri A, D'Andrea M, Marcelli F, Cominelli E. Primary prevention of deep venous thrombosis and pulmonary embolism in acute spinal cord injured patients. Spinal Cord 2002;40(6):300-3. doi: $\quad 10.1038 /$ sj.sc.3101298 [PubMed] [CrossRef] [Google Scholar]

55. 2. Jones T, Ugalde V, Franks P, Zhou H, White RH. Venous thromboembolism after spinal cord injury: incidence, time course, and associated risk factors in 16,240 adults and children. Arch Phys Med Rehabil 2005;86(12):2240-7. doi: 10.1016/j.apmr.2005.07.286 [PubMed] [CrossRef] [Google Scholar]

56. 3. Furlan JC, Fehlings MG. Role of screening tests for deep venous thrombosis in asymptomatic adults with acute spinal cord injury: an evidence-based analysis. Spine 2007;32(17):1908-16. doi:
10.1097/BRS.0b013e31811ec26a [PubMed] [CrossRef] [Google Scholar]

57. Khazaeipour, Z., Hajiaghababaei, M., Mirminachi, B., Vaccaro, A. R., \& RahimiMovaghar, V. (2017). Social support and its association with depression, gender and socioeconomic indicators in individuals with spinal cord injury in Iran. Spinal cord, 55(11), 1039-1044. https://doi.org/10.1038/sc.2017.80.

58. Fractures and joint injuries. By R. WatsonJones, B.Sc., M.Ch. Orth., F.R.C.S., Consultant in Orthopædic Surgery to the Royal Air Force; Director of Orthopædic and Accident Service, The London Hospital; etc. Third edition. In two volumes. Vol. II. $95 / 8 \times 65 / 8$ in. Pp. 409 960, with 745 illustrations. 1943. Edinburgh: E. \& S. Livingstone. Vols. I and II, 75s. net the set April 1944 https://doi.org/10.1002/bjs.18003112422 